University of Nebraska - Lincoln

DigitalCommons@University of Nebraska - Lincoln

Faculty Publications: Department of Entomology

Entomology, Department of

$10-3-2021$

\title{
Molecular characterization of western corn rootworm pyrethroid resistance
}

\author{
Dariane Souza \\ University of Nebraska-Lincoln, dariane.souza@ufl.edu \\ Blair D. Siegfried \\ University of Florida, bsiegfried1@ufl.edu \\ Lance Meinke \\ University of Nebraska-Lincoln, Imeinke1@unl.edu \\ Nicholas J. Miller \\ University of Nebraska-Lincoln, nmiller11@iit.edu
}

Follow this and additional works at: https://digitalcommons.unl.edu/entomologyfacpub

Part of the Entomology Commons

Souza, Dariane; Siegfried, Blair D.; Meinke, Lance; and Miller, Nicholas J., "Molecular characterization of western corn rootworm pyrethroid resistance" (2021). Faculty Publications: Department of Entomology. 962.

https://digitalcommons.unl.edu/entomologyfacpub/962

This Article is brought to you for free and open access by the Entomology, Department of at DigitalCommons@University of Nebraska - Lincoln. It has been accepted for inclusion in Faculty Publications: Department of Entomology by an authorized administrator of DigitalCommons@University of Nebraska - Lincoln. 


\title{
Molecular characterization of western corn rootworm pyrethroid resistance
}

\author{
Dariane Souza, ${ }^{1}$ Blair D. Siegfried, ${ }^{2}$ \\ Lance J. Meinke, ${ }^{1}$ and Nicholas J. Miller ${ }^{3}$
}

\begin{abstract}
1 Department of Entomology, University of Nebraska-Lincoln, Lincoln, NE 2 Entomology and Nematology Department, University of Florida, Gainesville, FL 3 Department of Biological Sciences, Illinois Institute of Technology, Chicago, IL

Correspondence - D Souza, Entomology and Nematology Department, University of Florida, Gainesville, FL 32611, USA; email dariane.souza@ufl.edu
\end{abstract}

ORCID: Dariane Souza https://orcid.org/0000-0003-3681-9053

\begin{abstract}
Background: Western corn rootworm (WCR) pyrethroid resistance has been confirmed in the western US Corn Belt. Toxicological and biochemical studies indicated that multiple mechanisms of resistance might be involved in the resistance trait, such as enhanced metabolism and/or kdr target-site mutation(s) in the voltage-gated sodium channels. To characterize the mechanisms of WCR pyrethroid resistance at the molecular level, pairwise comparisons were made between RNA-Seq data collected from pyrethroid-resistant and -susceptible WCR populations. Gene expression levels and sodium channel sequences were evaluated.

Results: Seven transcripts exhibited significantly different expression ( $q \leq 0.05$ ) when comparing field-collected pyrethroidresistant (R-Field) and -susceptible (S-Field) WCR populations. Three of the differentially expressed transcripts were P450s overexpressed in R-Field (9.2-26.2-fold). A higher number (99) of differentially expressed transcripts was found when comparing laboratory-derived pyrethroid-resistant (R-Lab) and -susceptible (S-Lab) WCR populations. Eight
\end{abstract}

Published in Pest Managment Science 77 (2021), 860-868.

DOI:10.1002/ps.6090

Copyright (C) 2020 Society of Chemical Industry. Published by Wiley. Used by perrmission. Submitted 25 May 2020; revised 11 August 2020; accepted 18 September 2020; published 3 October 2020.

Supporting information is attached to the archive record for this article. 
of the significant transcripts were P450s overexpressed in R-Lab (2.7-39.8-fold). This study did not detect kdr mutations in pyrethroid-resistant WCR populations. Other differentially expressed transcripts that may play a role in WCR pyrethroid resistance are discussed.

Conclusion: This study revealed that P450-mediated metabolism is likely to be a major mechanism of WCR pyrethroid resistance, which could affect the efficacy of other insecticides sharing similar metabolic pathways. Additionally, results suggested that although laboratory selection of a pyrethroid-resistant WCR population may help to characterize resistance mechanisms, a field-selected population provided rare and perhaps major variants corresponding to the resistance trait.

Keywords: Diabrotica virgifera virgifera, western corn rootworm, pyrethroid resistance, insecticide resistance, RNA-Seq, P450

\section{Introduction}

Yield losses and management costs associated with the western corn rootworm (WCR), Diabrotica virgifera virgifera LeConte (Coleoptera: Chrysomelidae), have been estimated in excess of 1 billion dollars per year in the USA. ${ }^{1-3}$ Populations of this major pest of maize (Zea mays L.) have been continuously adapting to a variety of control tactics. ${ }^{4}$ Particularly in the western US Corn Belt, limited rotation of WCR management strategies and increased reliance on aerial applications of pyrethroid insecticides for adult suppression in addition to the use of soil insecticides for larval control have been imposing high selection pressure on WCR populations. ${ }^{5-8}$ As a result, multiple WCR populations in southwestern areas of Kansas and Nebraska have developed resistance to pyrethroids used in foliar (bifenthrin) and soil (bifenthrin, tefluthrin and cyfluthrin) formulations significantly impacting the performance of major insecticide products used for WCR control.9-11

The toxicity of pyrethroids depends mainly on the level of exposure and their ability to bind and disrupt voltage-gated sodium channels, although secondary target sites like voltage-gated calcium and chloride channels have also been reported. ${ }^{12-16}$ Mutations in the insect voltage-gated sodium channels can lead to reduced sensitivity to pyrethroid insecticides, and consequently to what is commonly referred to as knockdown resistance $(k d r) .{ }^{16,17} \mathrm{~A}$ variety of nonsynonymous amino acid substitutions in the sodium channel gene have been identified as $k d r$ mutations conferring pyrethroid resistance in insects. ${ }^{18}$ Since pyrethroids and dichloro-diphenyl-trichloroethane (DDT) share 
the same target site, $k d r$ mutations provide cross-resistance between these two insecticides, ${ }^{19-24}$ which could explain the DDT cross-resistance observed in pyrethroid-resistant WCR populations. ${ }^{25}$ However, an investigation of pyrethroid-resistant WCR sodium channels did not detect mutations that are commonly associated with $k d r$ resistance in other insect species, suggesting that if target-site insensitivity were associated with the resistance trait, it could represent a novel mutation not previously identified within Chrysomelidae. ${ }^{10}$

In addition to changes in target site sensitivity as described above, an elaborate system of enzymes such as cytochrome P450 microsomal monooxygenases (P450s), esterases and glutathione $S$-transferases act to metabolize and detoxify xenobiotic compounds ${ }^{26}$ and have commonly been associatedwith resistance in pest species. A number of instances of pyrethroid resistance in arthropods are related to enhanced metabolism involving esterases ${ }^{27-31}, \mathrm{P} 450 \mathrm{~s}, 32-40$ and glutathione $S$-transferases. ${ }^{41-44}$ It was previously reported that WCR resistance to pyrethroids was partially suppressed by inhibitors of esterases and $\mathrm{P} 450 \mathrm{~s},{ }^{25}$ and that the activity of these enzymes was higher in pyrethroid-resistant WCR populations..$^{10}$ Collectively, these investigations suggest that enhanced metabolism may be a major contributor to pyrethroid resistance in WCR. 10,25 The current study was conducted to test this hypothesis at the molecular level and to characterize the differential gene expression of pyrethroid-resistant WCR individuals.

\section{Materials and methods}

\subsection{WCR populations}

Four independent WCR adult populations were tested throughout this study. In 2016, WCR beetles were collected from Saunders County (S-Field) and Keith County (R-Field) (Nebraska, USA) representing field-derived pyrethroid-susceptible and -resistant populations, respectively. The Keith County collection site represented a commercial field where continuous maize production plus annual soil- and aerial pyrethroid applications had been used for at least five consecutive years prior to this study. The Saunders County field was located at the University of Nebraska Eastern Nebraska Research and Extension 
Center, which is surrounded by a large area of continuous maize that had not received insecticide aerial applications for over 10 years. Pyrethroids had only been soil-applied at that site in a few small-plot trials. A pyrethroid-resistant nondiapausing population reared for nine generations under adult bifenthrin selection (R-Lab) ${ }^{10}$ and a nondiapausing control purchased from Crop Characteristics, Inc., Farmington, MN (S-Lab) were also used to represent lab-derived genotypes. R-Lab was originally established in 2014 by mating pyrethroid-resistant males from Perkins County, NE with susceptible non-diapausing females from S-Lab. ${ }^{10}$ Susceptibility levels against bifenthrin, tefluthrin and cyfluthrin had been previously documented for the WCR populations tested in this study at the adult 25,45 and larval stages ${ }^{11,25}$. Relative to $\mathrm{S}$-Lab, bifenthrin resistance ratios $\left(R_{50}\right)$ estimated for S-Field, R-Field and R-Lab adults were 13.1, 39.6 and 37.9, respectively. ${ }^{45}$ WCR control failure had been observed for R-Field and R-Lab, but not for S-Field or S-Lab. ${ }^{11,45}$ Both field collected and laboratoryderived populations were reared simultaneously for one generation prior to nucleic acid extractions using standard laboratory rearing procedures. ${ }^{5}$ All populations were maintained under laboratory conditions of $23 \pm 1{ }^{\circ} \mathrm{C}$ and $13 \pm$ $1 \mathrm{~h}$ photophase in the Department of Entomology, University of Nebraska, Lincoln, NE. In 2017, WCR beetles (48 h-old) were transferred from rearing cages to individual microcentrifuge tubes, flash-frozen in liquid nitrogen immediately and stored at $-80^{\circ} \mathrm{C}$ until RNA and DNA extractions.

\subsection{RNA extraction and library preparation}

Total RNA was individually extracted from whole bodies of 10 adults ( $n=10$ biological replicates) of each WCR population (1:1 sex ratio) using a Qiagen RNeasy mini kit (Cat No. 74104, Germantown, MD, USA) according to the manufacturer's instructions. RNA concentration and quality were determined by spectrophotometry using a Nanodrop 2000 (Thermo Scientific, Waltham, MA, USA) and fluorimetry using Qubit (Thermo Scientific). In addition, an Agilent 2100 Bioanalyzer (Santa Clara, CA, USA) was used for assessment of the relative RNA Integrity Number equivalent (RINe) as a quality metric. Barcoded mRNA-Seq libraries $(n=40)$ were prepared by polyA selection and sequenced in three lanes of Illumina HiSeq 4000 to an 
expected sequencing depth of $\sim 26$ million reads per sample. Quality assessment of samples and sequencing were performed by Genewiz, South Plainfield, NJ, USA.

\subsection{Gene expression analysis}

A web interface provided by the national cyberinfrastructure CyVerse in the Discovery Environment ${ }^{46,47}$ was used for the RNA-Seq analyses. Data analysis of laboratory and field populations followed the same workflow in separate pairwise comparisons. Low quality bases and IIlumina adapter sequences were trimmed from paired reads using the Trimmomatic 0.36 program ${ }^{48}$ with the following parameters: ILLUMI NACLIP:contaminants:2:30:10, LEADING:3, TRAILING:3, HEADCROP:7, CROP:138, SLIDINGWINDOW:5:20, MINLEN:50. FastQC 0.11.549 was used to evaluate the qualities of raw and trimmed sequencing data. Trimmed reads were aligned to the WCR genome (NCBI, BioProject: PRJNA432972) using HISAT2 $2.1^{50}$ and transcripts assembled with StringTie 1.3.3. ${ }^{51} \mathrm{~A}$ single transcript sequence was obtained using StringTie 1.3.3-merge ${ }^{52}$ and used to build an index file in Kallisto 0.42 .3 -index..$^{53}$ An alignment-free transcript quantification approach was then performed for each paired-read using Kallisto 0.42.3-quant ${ }^{53}$ with 100 bootstrap iterations to provide a measure of the accuracy of the quantification by random resampling with replacement. Pairwise comparisons of Kallisto quantification outputs were made between pyrethroidresistant and pyrethroid-susceptible WCR populations using sleuth 0.29 .0 package $^{54}$ in R 3.5.0 software (R Foundation for Statistical Computing, Vienna, Austria). A likelihood ratio test (LRT) was performed to verify goodness of fit of transcripts to the full statistical model that considers the pyrethroid resistance status as a factor. Considering a correction of $P$ values for type I error of false positives, that is false discovery rate (FDR) correction, expression levels with $q \leq 0.05$ were considered significant. Transcripts expressed significantly differently were translated into amino acid sequences using EMBOSS Transeq - https://www.ebi.ac.uk/Tools/st/emboss transeq/. ${ }^{55}$ Sequence similarity searches were performed for the longest open reading frames (ORFs) of significant transcript sequences on NCBI BLASTx/BLASTp, ${ }^{56}$ Inter-Pro Scan ${ }^{57}$ and i5K Workspace@ NAL. ${ }^{58}$ Also, pairwise local protein sequence alignment between 
some significant transcripts were performed in EMBOSS Water https://www.ebi.ac.uk/Tools/psa/emboss water/ ${ }^{55}$ — with default settings (matrix:BLOSUM62; gap penalty:10; and extension penalty:0.5) to verify similarity between them.

\subsection{WCR voltage-gated sodium channel gene screening}

Voltage-gated sodium channel amino acid sequences from Colorado potato beetle (CPB) Leptinotarsa decemlineata (Say) and Asian longhorned beetle (ALB) Anoplophora glabripennis (Motschulsky) were used to localize homologous sequences in the WCR transcriptome. Similarity searches were performed with local tBLASTn where the CPB and ALB protein sequences available from NCBI (Accessions: XP_023023069.1 and XP_018568941.1, respectively) were used as queries and the WCR genome was used as database. Sequences identified in tBLASTn were filtered from HISAT2 alignment bam files and then merged using Samtools $1.7^{59}$ available in the Discovery Environment of CyVerse. ${ }^{46,47}$ The resulting merged file was screened for nonsynonymous nucleotide substitutions in Tablet 1.17.08.17. ${ }^{60}$ using the visual application for tag variants. In addition, the sequences from CPB and ALB used earlier in tBLASTn were aligned to sequences extracted from the WCR sodium channel scaffold and to the sodium channel sequence of housefly Musca domestica L. (Vssc 1 ) in GenBank (Acession No: AAB47604) using T-Coffee (https://www.ebi. ac.uk/ Tools/msa/tcoffee/). ${ }^{61}$ The predictions of WCR sodium channel domain structures and transmembrane segments were performed with SMART (http://smart.embl-heidelberg.de/ ), ${ }^{62}$ HMMER 3.2.1 (https://www.ebi.ac.uk/Tools/hmmer/ ) ${ }^{63,64}$ and TMHMM v.2.0 (http://www.cbs.dtu.dk/services/TMHMM/ ). ${ }^{65}$

\subsection{DNA sanger sequencing $k d r$ investigation}

Two putative nonsynonymous substitutions found in the voltagegated sodium channel screening, numbered L1422 and A1558 in Vssc 1, were investigated in WCR populations by Sanger sequencing. Genomic DNA was extracted individually from 10 adults (1:1 sex ratio) of each WCR population using a Qiagen DNeasy kit (Cat No. 69504) according to the manufacturer's instructions. Polymerase chain reactions (PCR) were performed in a $50 \mu \mathrm{L}$ final reaction volume containing $100 \mathrm{ng}$ of 
template DNA, 1 unit of GoTaq ${ }^{\circledR}$ Flexi DNA polymerase, $1 \times$ Colorless GoTaq ${ }^{\circledR}$ Flexi buffer (Cat No. M8291, Promega, Madison, WI, USA), $0.2 \mathrm{mM}$ dNTP, $1.5 \mathrm{mM} \mathrm{MgCl}_{2}$ and $0.2 \mu \mathrm{M}$ of each primer. The PCR temperature profile for each fragment included an initial heating step at $95{ }^{\circ} \mathrm{C}$ for 2 min, followed by 35 cycles of $94{ }^{\circ} \mathrm{C}$ for $30 \mathrm{~s}$, annealing temperatures for $90 \mathrm{~s}, 72^{\circ} \mathrm{C}$ for $1 \mathrm{~min}$, and a final extension of $60^{\circ} \mathrm{C}$ for $30 \mathrm{~min}$. The forward (5'-CCTTAAACCGTCACTGGCAG-3') and reverse (5'-ACAAGCATTCACATCAGGGA-3') primers were used with an annealing temperature of $59{ }^{\circ} \mathrm{C}$ to amplify a $492 \mathrm{bp}$ region surrounding the site L1422. Also, forward (5'-TGAGCAGATGGGACGTGAAT-3') and reverse (5'-AATCGCAACTTTTCCGCACT-3') primers were used with an annealing temperature of $56^{\circ} \mathrm{C}$ to amplify a $411 \mathrm{bp}$ region surrounding the A1558 location. Primers were designed in Primer3web version 4.0.0.66,67 DNA concentration and quality before and after PCR were determined by Nanodrop 2000 (Thermo Scientific). PCR products were analyzed by $1.3 \%$ agarose gel electrophoresis, purified with QIAquick PCR Purification Kit and sequenced by Genewiz, South Plainfield, NJ with the Applied Biosystems (ABI) 3730 DNA Analysis Instrument (Life Technologies, Grand Island, NY, USA). Sequences were aligned and mapped to the WCR sodium channel gene contig using Geneious Basic 5.6.768, and screened for targeted $k d r$ polymorphisms.

\section{Results}

\subsection{RNA extraction and library preparation}

All RNA samples used for library preparation were of high integrity with an average A260/A280 $=2.12$ and RINe $=10$. The Illumina HiSeq platform produced a total of 1.29 billion paired-reads of $150 \mathrm{bp}$ in length, yielding 389876 Mbases with a mean quality score of 37.96 (91\% bases $\geq$ Q30). An average of $32.3 \pm 0.5$ (SE) million reads were produced per library. Illumina sequencing data from this study have been submitted to the NCBI BioProject (https://www.ncbi.nlm.nih.gov/bioproject ) under accession number PRJNA430262. These data are also available through the NCBI Sequence Read Archive (SRA; https://www.ncbi.nlm.nih.gov/sra ) under accession numbers that go from SRX3594800 through SRX3594839. 


\subsection{Gene expression analysis}

Out of 53929 assembled transcripts from WCR field populations, seven were differentially expressed and expressed at a higher level in the pyrethroid-resistant R-Field compared to the -susceptible SField population ( $q \leq 0.05$ ) (Tables S1 and S3). Similarity searches of translated amino acid sequences predicted that three of the tran-

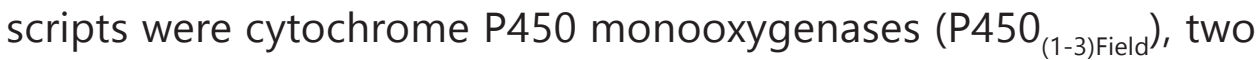
were transcription factors and one was a junctophilin (Figure 1). The

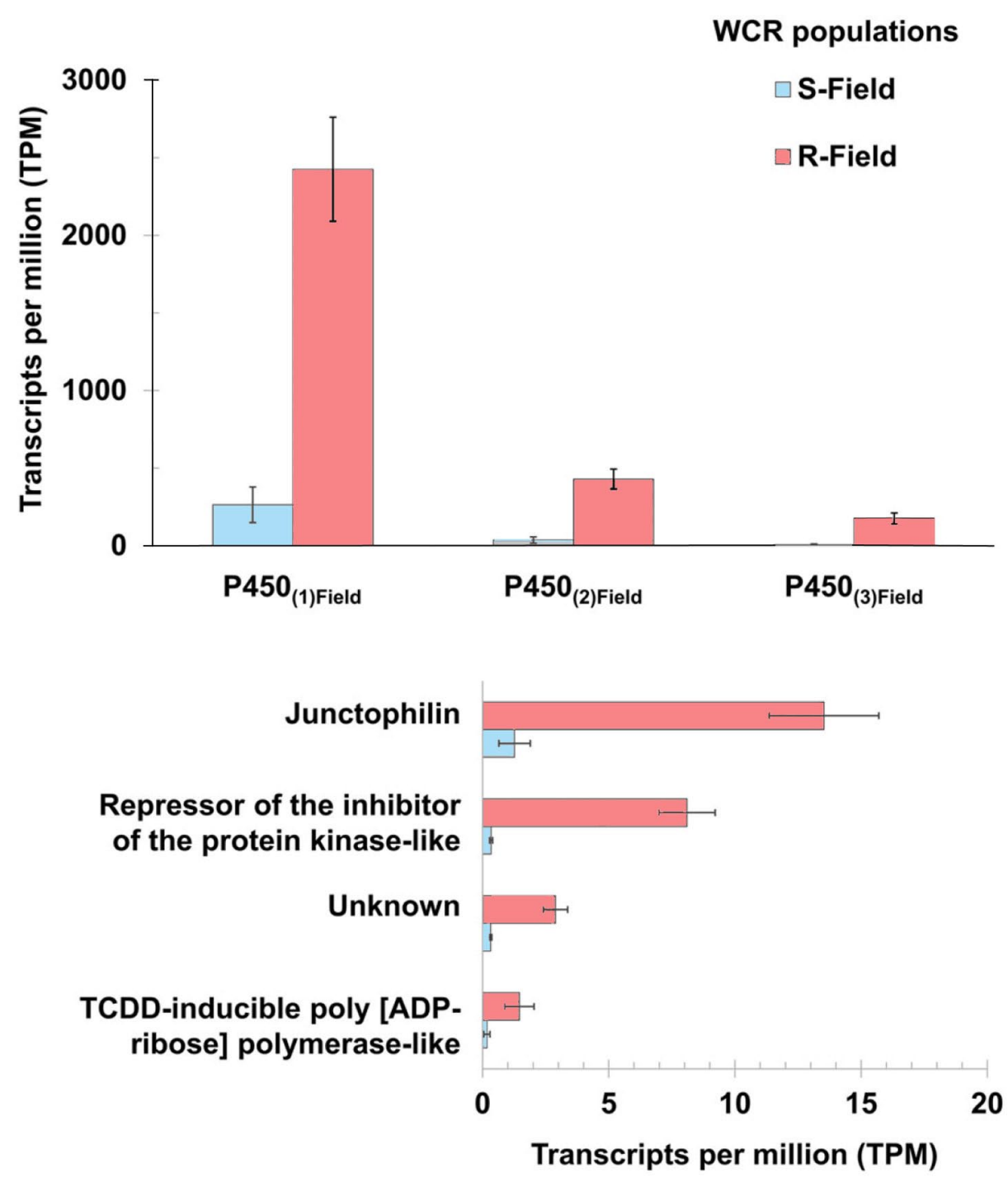

Figure 1. Transcripts differentially expressed $(q \leq 0.05)$ in pairwise comparisons between field-derived WCR populations known to be susceptible (S-Field) and resistant (R-Field) to pyrethroids. Graphs show the transcript mean abundance in transcripts per million (TPM) units \pm SE. 
Table 1. Abundance ratios of P450 transcripts differentially expressed ( $q \leq 0.05)$ in pairwise comparisons within laboratory- or field-derived WCRpopulations known to be susceptible (S-) and resistant (R-) to pyrethroids

\begin{tabular}{|c|c|c|c|}
\hline $\begin{array}{l}\text { P450 } \\
\text { candidates }\end{array}$ & $\begin{array}{c}\text { ORF size } \\
\text { (aa) }\end{array}$ & 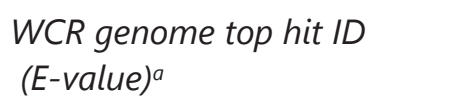 & $\begin{array}{l}\text { Abundance ratio } \\
R_{-(T P M)} / S_{-(T P M)}{ }^{b}\end{array}$ \\
\hline P450 (1)Field & 146 & XM_028285602.1 (1.17e-50) & 9.17 \\
\hline P450 (2)Field & 158 & XM_028294106.1 (6.61e-103) & 11.77 \\
\hline P450 (3)Field & 166 & XM_028285602.1 (4.03e-51) & 26.18 \\
\hline P450 (1)Lab & 182 & XM_028285602.1 (5.55e-51) & 39.06 \\
\hline P450 (2)Lab & 120 & XM_028285602.1 (5.59e-75) & 28.14 \\
\hline P450 (3)Lab & 499 & XM_028285602.1 (1.27e-100) & 22.32 \\
\hline P450 (4)Lab & 158 & XM_028285602.1 (1.92e-102) & 47.18 \\
\hline P450 (5)Lab & 158 & XM_028294106.1 (6.61e-103) & 39.84 \\
\hline P450 (6)Lab & 499 & XM_028289555.1 (6.4e-180) & 2.70 \\
\hline P450 & 288 & XM_028297637.1 (0) & 8.71 \\
\hline P450 (8)Lab & 442 & XM_028290131.1 (0) & 7.28 \\
\hline P450 (9)Lab & 292 & XM_028294105.1 (0) & 0.04 \\
\hline P450 (10)Lab & 139 & XM_028289556.1 (2.11e-49) & 0.12 \\
\hline
\end{tabular}

a. i5k Workspace@NAL ( https://i5k.nal.usda.gov/webapp/blast/ ) tBLASTn; Database: Diabrotica virgifera genome assembly GCA_003013835.2.

b. TPM, mean abundance in transcripts per million (TPM) units.

transcript mean abundances of $\mathrm{P} 450_{(1) \text { Field' }} \mathrm{P} 450_{(2) \text { Field }}$ and $\mathrm{P} 450_{(3) \text { Field }}$ were 9.2-, 11.8-, and 26.2-times greater in R-Field than in S-Field, respectively (Table 1 ). The two transcription factor candidates were 8.5- and 23.9-times more abundant in R-Field. The mean abundance of predicted junctophilin (100\% identity and query cover to either ALB or CPB in BLASTp) was 10.7-times greater in R-Field than in S-Field. No sequence similarity was found for one of the significant transcripts overexpressed in R-Field.

For pairwise comparison between the laboratory unselected (SLab) and bifenthrin-selected (R-Lab) WCR populations, 47255 transcripts were analyzed and 99 exhibited significantly different expression ( $q \leq$ 0.05). A total of 64 significant transcripts were expressed at a higher level in the pyrethroid-resistant R-Lab population whereas 35 were expressed at a lower level in the same population (Tables S2 and S3). Protein similarity searches suggested that 10 of the transcripts differentially expressed between laboratory-derived populations were P450s (P450 (1-10)Lab $)$ (Figure 2 ) and for eight of them (P450 $\left.{ }_{(1-8) \text { Lab }}\right)$, the 


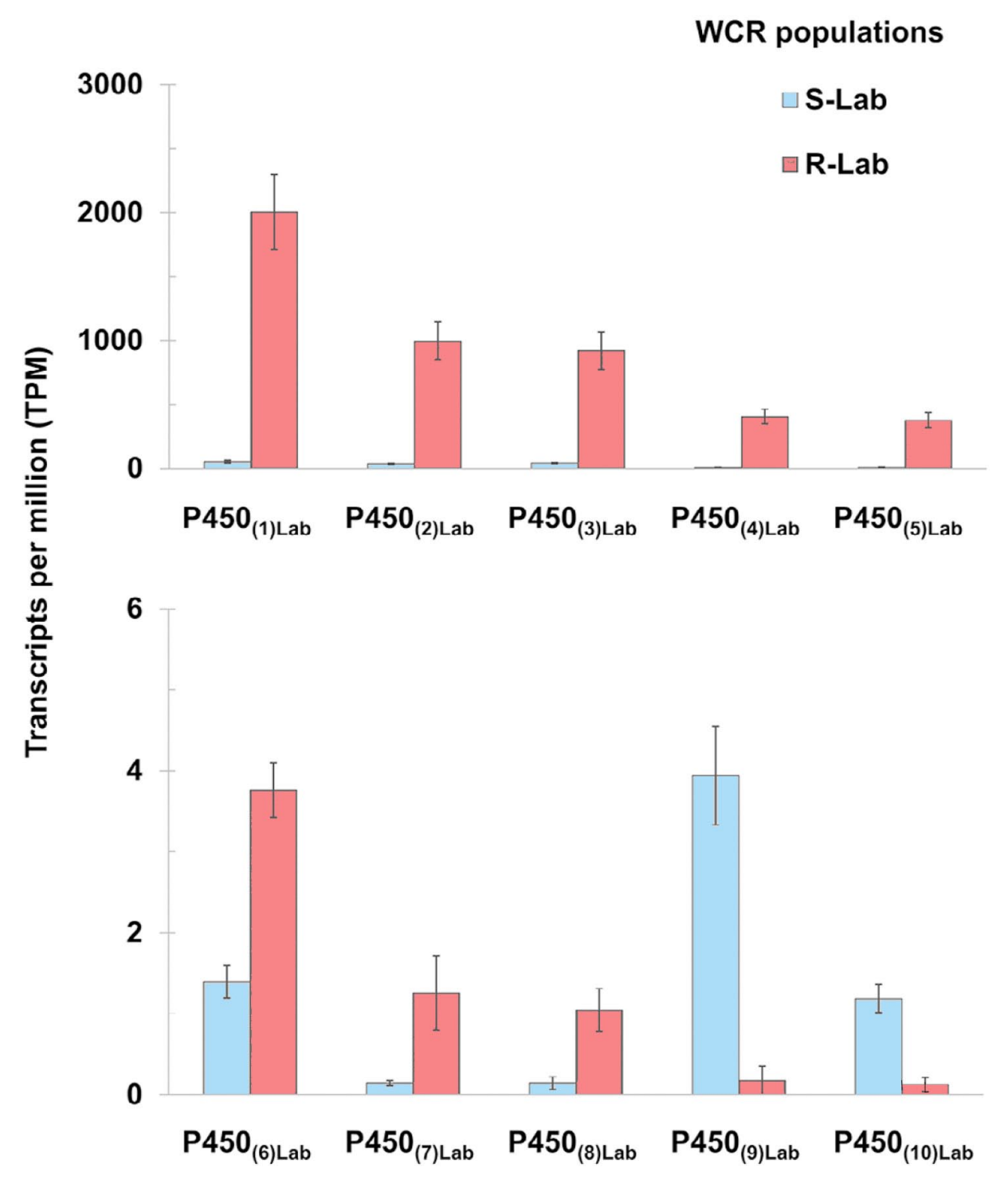

Figure 2. P450 transcripts differentially expressed $(q \leq 0.05)$ in pairwise comparisons between laboratory-derived WCR populations known to be susceptible (S-Lab) and resistant (R-Lab) to pyrethroids. Graphs show the transcript mean abundance in transcripts per million (TPM) units $\pm \mathrm{SE}$.

mean abundance in RLab was 2.7 to 39.8 times greater than in S-Lab (Table 1). Two P450s (P450 (9-10)Lab) and three enzymes also involved in oxidative metabolic processes appear to be underexpressed in the RLab population along with 13 other predicted proteins (Table 2). The mean abundance of $\mathrm{P} 450_{(9) \text { Lab }}$ and $\mathrm{P} 450_{(10) \text { Lab }}$ was 22.6 and 9.5 times lower in R-Lab than in S-Lab, respectively (Figure 2 and Table 1). 
Table 2. Predicted identity and function of transcripts differentially expressed ( $q \leq 0.05)$ in the pyrethroid-resistant laboratory population R-Lab

\begin{tabular}{|c|c|c|}
\hline \multirow[b]{2}{*}{ Predicted function } & \multicolumn{2}{|l|}{ Proteins predicted (no. of targets) ${ }^{a}$} \\
\hline & Overexpressed & Underexpressed \\
\hline Oxidation & P450s (8) & $\begin{array}{l}\text { P450s (2), lysyl oxidase (1), } \\
\text { Glyoxylate/hydroxypyruvate } \\
\text { reductase (1), Sorbitol } \\
\text { dehydrogenase (1) }\end{array}$ \\
\hline Hydrolysis & $\begin{array}{l}\text { Carboxypeptidase (1), maltase (1), } \\
\text { beta-hexosaminidase (1), chitinase (1), } \\
\text { aldose-epimerase (1), myrosinase (1), } \\
\text { glycoside hydrolase (1) }\end{array}$ & $\begin{array}{l}\text { Myrosinase (1), } \\
\text { beta ureidopropionase (1) }\end{array}$ \\
\hline Conjugation & & Glutathione S-transferase (1) \\
\hline Proteolysis & Cysteine proteinases (2) & \\
\hline Transporter & $\begin{array}{l}\text { ABC transporters }(4), \text { sugar transporters }(2) \text {, } \\
\text { peptide transporters }(4)\end{array}$ & \\
\hline Transcription factors & $\begin{array}{l}\text { Zinc finger type proteins (4), nuclear } \\
\text { factor NF-kappa-B p110 subunit-like (1), } \\
\text { transcription activator MBF2 family (1) }\end{array}$ & Zinc finger type proteins (2) \\
\hline Nervous system & $\begin{array}{l}\text { E3 ubiquitin-protein ligase MYCBP2 (1), } \\
\text { neprilysin (1) }\end{array}$ & \\
\hline Immune response & $\begin{array}{l}\text { Coleoptericin (1), leucine-rich repeat } \\
\text { protein SHOC-2-like (1) }\end{array}$ & \\
\hline Membrane barrier & Tetraspanin-2A (1) & \\
\hline Catalysis & $\begin{array}{l}\text { Uridine phosphorylase (1), glutamine- } \\
\text { fructose-6-phosphate aminotransferase } 2 \text { (1) }\end{array}$ & \\
\hline Cell division & Protein skeletor, isoform B/C (1) & Dynactin subunit 2 (1) \\
\hline Other & $\begin{array}{l}\text { Reverse transcriptase (3), laminin subunit } \\
\text { gamma-1-like (1), galectin (1), mucin (1) }\end{array}$ & $\begin{array}{l}\text { Reverse transcriptase (2), heat } \\
\text { shock protein beta-1 (1), } \\
\text { elongation factor Tu (1), } \\
\text { retrovirus-related Pol } \\
\text { polyprotein LINE-1 (1), } \\
\text { alphatocopherol transfer } \\
\text { protein-like (1), } \\
\text { asialoglycoprotein receptor } \\
\text { 2/C-type lectin precursor (1) }\end{array}$ \\
\hline
\end{tabular}

a. Sequences, similarity search results and putative GO annotations can be found in Table S2. 
The longest and most complete P450 transcript sequences ( 500 amino acids) differentially expressed among all WCR populations tested were P450 (3)Lab $\left(499\right.$ amino acids), P450 ${ }_{(6) \text { Lab }}$ (499 amino acids) and $\mathrm{P} 450_{(8) \text { Lab }}$ (442 amino acids). All remaining P450 transcripts were translated into shorter amino acid sequences ( $<300$ amino acids) (Table 1). Sequence identity between the longest P450 transcripts and all remaining significant P450s ranged from 25\% to 100\% (Table 3). Protein search databases revealed that all P450s differentially expressed in either field-derived or laboratory-derived WCR populations presented $>40 \%$ sequence identity to CYP6-like P450 proteins from other Coleoptera species (Tables S1 and S2).

Cellular functions predicted for remaining transcripts differentially expressed in laboratory-derived populations are described in Table 2. Among them, at least seven hydrolases, four $A B C$ transporters, two sugar transporters, six transcription factors and two nervous systemrelated transcripts (E3 ubiquitin-protein ligase and neprilysin) were overexpressed in the pyrethroid-resistant WCR population R-Lab (Table 2). No sequence similarity was found in protein search databases for 23 significant transcripts (17 underexpressed and six overexpressed in R-Lab), and thus they are of unknown identity and function.

Table 3. Percentage identity matrix of local alignments performed between ORFs of P450 transcripts differentially expressed $(q \leq 0.05)$ in WCR populations

Longest ORFs (>400 amino acids)

\begin{tabular}{|c|c|c|c|c|}
\hline P450 candidate & Transcript ID ${ }^{a}$ & $P 450_{(3) L a b}$ & $P 450_{(6) L a b}$ & $P 450_{(8) L a b}$ \\
\hline P450 (1)Field & MSTRG.24908.1 & 99.3 & 51.7 & 50.3 \\
\hline P450 (2)Field & MSTRG.75696.1 & 93.7 & 47 & 45.6 \\
\hline P450 (3)Field & MSTRG.24907.1 & 88.9 & 48.5 & 50.3 \\
\hline P450 (1)Lab & MSTRG.19112.1 & 88.4 & 48.2 & 50.3 \\
\hline P450 (2)Lab & MSTRG.63174.1 & 100.0 & 29.2 & 25.8 \\
\hline P450 (3)Lab & MSTRG.22143.1 & * & 41.9 & 39.6 \\
\hline P450 & MSTRG.71693.1 & 98.7 & 47.7 & 46.2 \\
\hline P450 & MSTRG.59366.1 & 93.7 & 47.0 & 45.6 \\
\hline P450 (6)Lab & MSTRG.36287.1 & 41.9 & * & 51.7 \\
\hline P450 & MSTRG.3101.1 & 38.1 & 41.2 & 42.7 \\
\hline P450 (8)Lab & MSTRG.24813.1 & 39.6 & 51.7 & * \\
\hline P450 (9)Lab & MSTRG.56151.1 & 36.5 & 35.6 & 34.1 \\
\hline P450 (10)Lab & MSTRG.66987.1 & 51.9 & 98.5 & 53.1 \\
\hline
\end{tabular}

a. Sequences, similarity search results and putative GO annotations of each transcript ID can be found in Tables S1 and S2. 


\subsection{WCR voltage-gated sodium channel gene screening}

Two potential nonsynonymous substitutions were found in the voltage-gated sodium channel gene of some individuals from the $\mathrm{R}$-Lab and R-Field populations when screening the RNA-Seq reads against the WCR genome. Locations of substitutions were L1422P and $\mathrm{A} 1558 \mathrm{I}$ in Vssc 1 (Figure S1), which could be $k d r$ mutations not reported previously in pyrethroid-resistant insects. However, the sequencing coverage at those regions was too low to enable confirmation. Voltage-gated sodium channel domain structures and transmembrane segments were predicted (Figure S1) along a 2040 amino acid sequence for WCR (Figure S2).

\subsection{DNA sanger sequencing $k d r$ investigation}

Relative to the pyrethroid-susceptible individuals from populations S-Lab and S-Field, no mutations were found for the L1422 and A1558 loci in pyrethroid-resistant WCR. However, the 411 bp PCR product covering the A1558 locus did not amplify in all WCR samples (Figure S3) and therefore fewer sequences (14 out of 40) were compared at this locus.

\section{Discussion}

This study supports the hypothesis that constitutive enhanced metabolism of pyrethroid insecticides such as bifenthrin, tefluthrin and cyfluthrin is a mechanism of WCR pyrethroid resistance and suggests that P450s may play a major role in the resistance trait. Although several hydrolytic enzymes were differentially expressed in laboratory-derived WCR populations, P450s were the only metabolism-related genes exhibiting significantly different expression in field-derived WCR populations. In fact, nearly $50 \%$ of transcripts differentially expressed in the field-derived pyrethroid-resistant WCR populations were overexpressed P450s as well as $\sim 13 \%$ of transcripts overexpressed in the laboratoryselected pyrethroid-resistant WCR population. Enhanced oxidative metabolism resulting from the overproduction of P450 enzymes has been commonly observed in 
pyrethroid-resistant arthropods ${ }^{33,34,36-39,69}$ since it can accelerate the production of metabolites that are less toxic, less stable and are unable to reach the target site. ${ }^{26}$

The overexpression of P450s observed in resistant insects may be derived from gene amplification and/or from up-regulation of expression caused by substitutions, insertions and deletions in promoter sequences and/or regulatory loci. ${ }^{70-72}$ Further investigation is necessary to identify not only the mechanism behind P450s overexpression in pyrethroid-resistant WCR but also specific P450 genes involved. A detailed annotation and phylogeny of all WCR P450 genes is part of an ongoing effort to annotate the WCR genome and will be published elsewhere. Most P450 proteins are $\sim 500$ amino acids long, ${ }^{73}$ and it is likely that the majority of differentially expressed P450 transcripts were fragments of longer gene sequences as the translated protein sequences were $\sim 200$ amino acids. Although incomplete sequences prevent the identification of specific encoding P450 genes, all differentially expressed P450 transcripts shared $>40 \%$ similarity to Coleoptera CYP6 proteins in protein search databases. Results from local alignments and the variable expression observed between transcripts suggest that multiple P450 genes may be involved in WCR pyrethroid resistance. Also, differences in percent identity of amino acid sequences may suggest that P450s overexpressed in the fieldderived pyrethroid-resistant population are related but not necessarily the same P450 genes, or are isoforms overexpressed in the pyrethroid selected laboratory population. These results support the variable activity of P450-mediated $\mathrm{O}$-demethylation observed previously when comparing laboratory-selected and field-derived pyrethroid-resistant WCR populations. ${ }^{10}$

The number of transcripts differentially expressed between resistant and susceptible WCR populations was higher when comparing laboratory-selected individuals with the laboratorysusceptible individuals, which supports the suggestion that artificial insecticide selection favors a polygenic response..$^{74,75}$ Our results indicate that although laboratory selection of pyrethroidresistant WCR populations is useful for predictions and investigations of resistance mechanisms, the heterogeneity and population dynamics present in the field are more likely to provide conditions for detection of rare and perhaps major variants contributing to resistance. ${ }^{76,77}$ Several hydrolytic enzymes 
and $A B C$ transporters commonly associated with insecticide resistance 28,39,78-80 were overexpressed in the laboratory-selected WCR population whereas their expression were not significantly different in the field-derived resistant population. However, the correlation between transcript levels and protein activity is not necessarily linear in resistant insects. ${ }^{81-83}$ Qualitative changes in esterases are suggested by their higher biochemical activity in field-derived pyrethroid-resistant WCR populations ${ }^{10}$ in which transcript levels remain unchanged. Insecticides such as pyrethroids, carbamates and organophosphates share the common structural feature of ester bonds between alcohol and acid moieties and are therefore susceptible to hydrolysis catalyzed by esterases. ${ }^{84-86}$ Qualitative changes of esterases may play a role in pyrethroid enhanced metabolism, reduced efficacy of the organophosphate dimethoate and negative cross-resistance with indoxacarb previously observed in pyrethroid-resistant WCR populations, ${ }^{45}$ and requires further investigation to fully elucidate their role in resistance.

A previous investigation showed that bifenthrin resistance levels estimated from adult bioassays using active ingredients were similar for both the laboratory-selected and field-collected pyrethroidresistant WCR populations used in our study. ${ }^{45}$ However, this same investigation revealed that their susceptibility to commercial rates of a bifenthrin foliar formulation differed under aerial application simulations. It was found that the lowest bifenthrin application rate failed to control either the laboratory- or field-derived resistant adults while the highest application rate failed to control only fieldderived resistant populations ${ }^{45}$ Although both pyrethroid resistant WCR populations used in our study may share some mechanisms of resistance, gene variants and/or transcriptional levels present in the field-derived resistant WCR population could be more relevant in terms of practical resistance. ${ }^{87}$

Moreover, it should be noted that estimates of phenotypic and genotypic differences associated with a resistance trait are relative to the susceptible populations used for comparison. While the field-derived adult WCR population used in our study as a susceptible reference had previously shown to be effectively controlled by application rates of a bifenthrin foliar formulation, it was still approximately 10 -fold more tolerant to bifenthrin active ingredient than laboratory-derived susceptible populations. ${ }^{45}$ Thus, differences in expression between 
laboratory- and fieldderived WCR adults may also reflect the differential response to pyrethroids of the susceptible populations used in each comparison. Variation in number, relative abundance and identity of transcripts differentially expressed should be expected for different WCR populations and pairwise comparisons.

Pyrethroids bind to voltage-gated sodium channels caused a delay in channel closing and prolonged sodium inactivation. ${ }^{26}$ Repetitive action potentials are generated across neurons, ultimately disrupting the normal flow of information to the central nervous system. Some proteins with nervous system functions were also differentially expressed in the pyrethroid-resistant WCR populations tested and could play a role in the insecticide resistance trait. Junctophilin, overexpressed in the field-derived pyrethroid-resistant WCR population, is a protein commonly found in human neurons, where it is involved in coupling membrane neurotransmitter receptors and intracellular channels. ${ }^{88} \mathrm{~A}$ study showed that a junctophilin gene from Drosophila melanogaster Meigen is functionally equivalent to mammalian homologues and that flies with altered junctophilin expression also have marked neuronal alterations. ${ }^{89}$ The predicted E3 ubiquitinprotein ligase and neprilysin, overexpressed in the laboratoryselected pyrethroid-resistant WCR populations, also play a role in the nervous system of insects. Overexpression of the E3 ubiquitin-protein ligase gene in Drosophila glial cells causes synaptic impairments and down-regulation of $\mathrm{Na}+$ / $\mathrm{K}+$ pumps $^{90}$ whereas neprilysin modulates neuronal activity, viability and survival. ${ }^{91-93}$

This study did not detect $k d r$ mutations in pyrethroid-resistant WCR populations. However, the low RNA sequencing coverage of the WCR sodium channel prevented a thorough screen. Previous research found DDT cross-resistance in pyrethroid-resistant WCR strains ${ }^{25}$ and in most cases this is an indication of $k d r$ target-site mutation(s) in the voltage-gated sodium channels. ${ }^{19,94-96}$ Although $k d r$ mutation(s) cannot be excluded as a mechanism of WCR resistance, our results indicate that one or more P450s overexpressed in pyrethroid-resistant WCR populations may be causing both pyrethroid resistance and DDT crossresistance. Overexpression of some P450s, such as Cyp6g 1, have been associated with DDT cross-resistance in other species. ${ }^{97-100 ~ U n-~}$ derstanding the molecular basis of WCR pyrethroid resistance is critical to implement efficient resistance management strategies and to 
develop protocols for resistance detection. This study revealed that P450-mediated detoxification is probably a major mechanism positively selected in pyrethroid-resistant WCR populations, which could have an important impact on the efficacy of other insecticides sharing similar metabolic pathways. WCR pyrethroid resistance monitoring is recommended, and the P450 genes differentially expressed in this study could be further characterized and used for that purpose.

\section{$\diamond \diamond \diamond$}

Acknowledgments The authors would like to thank the Brazilian Ministry of Education Foundation CAPES for the financial support of the doctorate student involved in this study (proc No. 013398/2013-2100) and Monsanto for project funding (Corn Rootworm Knowledge Grant, No. 69292). The authors also would like to thank Dr Ana Maria Vélez and Dr Joe Louis (Entomology Department, University of NebraskaLincoln) for sharing their laboratory space and/or equipment for some of the experiments performed in this study.

Supporting information is attached to the archive record for this article.

\section{References}

1 Sappington TW, Siegfried BD and Guillemaud T, Coordinated Diabrotica genetics research: accelerating progress on an urgent insect pest problem. Am Entomol 52:90-97 (2006).

2 Dun Z, Mitchell PD and Agosti M, Estimating Diabrotica virgifera virgifera damage functions with field trial data: applying an unbalanced nested error component model. J Appl Entomol 134:409-419 (2010).

3 Wechsler S and Smith D, Has resistance taken root in U.S. corn fields? Demand for insect control. Am J Agric Econ 100:1136-1150 (2018).

4 Gray ME, Sappington TW, Miller NJ, Moeser J and Bohn MO, Adaptation and invasiveness of western corn rootworm: intensifying research on a worsening pest. Annu Rev Entomol 54:303-321 (2009).

5 Wangila DS, Gassmann AJ, Petzold-Maxwell JL, French BW and Meinke LJ, Susceptibility of Nebraska western corn rootworm (Coleoptera: Chrysomelidae) populations to Bt corn events. J Econ Entomol 108:742-751 (2015).

6 Archibald WR, Bradshaw JD, Golick DA, Wright RJ and Peterson JA, Nebraska growers' and crop consultants' knowledge and implementation of integrated pest management of western bean cutworm. J Integr Pest Manag 9:1-7 (2017). 
7 Tollefson J, Adult corn rootworm suppression to prevent oviposition. Proc Integr Crop Manag Conf 15:75-79 (1991).

8 Meinke LJ. Adult corn rootworm suppression: corn rootworm management in the transgenic era. APS Plant Manag Netw, 2014. http://www. plantmanagementnetwork.org/edcenter/seminars/ corn/AdultRootworm/ [accessed 20 July 2020].

9 Pereira AE, Wang H, Zukoff SN, Meinke LJ, French BW and Siegfried BD, Evidence of field-evolved resistance to bifenthrin in western corn rootworm (Diabrotica virgifera virgifera LeConte) populations in western Nebraska and Kansas. PLoS One 10:e0142299 (2015).

10 Souza D, Jiménez AV, Sarath G, Meinke LJ, Miller NJ and Siegfried BD, Enhanced metabolism and selection of pyrethroid-resistant western corn rootworms (Diabrotica virgifera virgifera LeConte). Pest Biochem Physiol 164:165-172 (2020).

11 Souza D, Peterson JA, Wright RJ and Meinke LJ, Field efficacy of soil insecticides on pyrethroid-resistant western corn rootworms (Diabrotica virgifera virgifera LeConte). Pest Manag Sci 76:827-833 (2020).

12 Ray DE, Sutharsan S and Forshaw PJ, Actions of pyrethroid insecticides on voltage-gated chloride channels in neuroblastoma cells. Neurotoxicology 18:755-760 (1996).

13 Hildebrand ME, McRory JE, Snutch TP and Stea A, Mammalian voltage-gated calcium channels are potently blocked by the pyrethroid insecticide allethrin. J Pharmacol Exp Ther 308:805-813 (2004).

14 Symington SB and Clark JM, Action of deltamethrin on N-type (Cav2.2) voltage-sensitive calcium channels in rat brain. Pest Biochem Physiol 82:1-15 (2005).

15 Breckenridge CB, Holden L, Sturgess N, Weiner M, Sheets L, Sargent D et al., Evidence for a separate mechanism of toxicity for the type I and the type II pyrethroid insecticides. Neurotoxicology 30:S17-S31 (2009).

16 Soderlund DM, Molecular mechanisms of pyrethroid insecticide neurotoxicity: recent advances. Arch Toxicol 86:165-181 (2011).

17 Soderlund DM and Knipple DC, The molecular biology of knockdown resistance to pyrethroid insecticides. Insect Biochem Mol Biol 33: 563-577 (2003).

18 Dong K, Du Y, Rinkevich F, Nomura Y, Xu P, Wang L et al., Molecular biology of insect sodium channels and pyrethroid resistance. Insect Biochem Mol Biol 50:1-17 (2014).

19 Williamson MS, Denholm I, Bell CA and Devonshire AL, Knockdown resistance $(k d r)$ to DDT and pyrethroid insecticides maps to a sodium channel gene locus in the housefly (Musca domestica). Mol Gen Genet 240:17-22 (1993).

20 Chandre F, Darriet F, Darder M, Cuany A, Doannio JMC, Pasteur N et al., Pyrethroid resistance in Culex quinquefasciatus from West Africa. Med Vet Entomol 12:359-366 (1998). 
21 Schuler TH, Martinez-Torres D, Thompson AJ, Denholm I, Devonshire AL, Duce IR et al., Toxicological, electrophysiological, and molecular characterisation of knockdown resistance to pyrethroid insecticides in the diamondback moth, Plutella xylostella (L.). Pest Biochem Physiol 59:169-182 (1998).

22 Brengues C, Hawkes NJ, Chandre F, Mccarroll L, Duchon S, Guillet P et al., Pyrethroid and DDT cross-resistance in Aedes aegypti is correlated with novel mutations in the voltage-gated sodium channel gene. Med Vet Entomol 17:87-94 (2003).

23 Enayati AA, Vatandoost $\mathrm{H}$, Ladonni $\mathrm{H}$, Townson $\mathrm{H}$ and Hemingway J, Molecular evidence for a kdr-like pyrethroid resistance mechanism in the malaria vector mosquito Anopheles stephensi. Med Vet Entomol 17:138-144 (2003).

24 Rodríguez MM, Bisset JA, De Armas $Y$ and Ramos F, Pyrethroid insecticideresistant strain of Aedes aegypti from Cuba induced by deltamethrin selection. J Am Mosq Control Assoc 21:437-445 (2005).

25 Pereira AE, Souza D, Zukoff SN, Meinke LJ and Siegfried BD, Crossresistance and synergism bioassays suggest multiple mechanisms of pyrethroid resistance in western corn rootworm populations. PLoS One 12:e0179311 (2017).

26 Yu SJ, The Toxicology and Biochemistry of Insecticides, 2nd edn. CRC Press, Boca Raton, FL (2014).

27 Dowd PF, Gagne CC and Sparks TC, Enhanced pyrethroid hydrolysis in pyrethroid-resistant larvae of the tobacco budworm, Heliothis virescens (F.). Pest Biochem Physiol 28:9-16 (1987).

28 Sogorb MA and Vilanova E, Enzymes involved in the detoxification of organophosphorus, carbamate and pyrethroid insecticides through hydrolysis. Toxicol Lett 128:215-228 (2002).

29 Young SJ, Gunning RV and Moores GD, The effect of piperonyl butoxide on pyrethroid-resistance-associated esterases in Helicoverpa armigera (Hübner) (Lepidoptera: Noctuidae). Pest Manag Sci 61: 397-401 (2005).

30 Young SJ, Gunning RV and Moores GD, Effect of pretreatment with piperonyl butoxide on pyrethroid efficacy against insecticideresistant Helicoverpa armigera (Lepidoptera: Noctuidae) and Bemisia tabaci (Sternorrhyncha: Aleyrodidae). Pest Manag Sci 62:114-119 (2006).

31 Kamita SG, Mulligan S, Cornel AJ and Hammock BD, Quantification of GST and esterase activities in pyrethrin-resistant mosquitoes using pyrethroid-like fluorescent substrates. Int J Pest Manag 62:276-283 (2016).

32 Lee SST and Scott JG, Microsomal cytochrome P450 monooxygenases in the house fly (Musca domestica L.): biochemical changes associated with pyrethroid resistance and phenobarbital induction. Pest Biochem Physiol 35:1-10 (1989).

33 Pittendrigh B, Aronstein K, Zinkovsky E, Andreev O, Campbell B, Daly J et al., Cytochrome P450 genes from Helicoverpa armigera: expression in a pyrethroid-susceptible and -resistant strain. Insect Biochem Mol Biol 27:507512 (1997). 
34 Kasai S and Scott JG, Overexpression of cytochrome P450 CYP6D1 is associated with monooxygenase-mediated pyrethroid resistance in house flies from Georgia. Pest Biochem Physiol 68:34-41 (2000).

35 Nikou D, Ranson H and Hemingway J, An adult-specific CYP6 P450 gene is overexpressed in a pyrethroid-resistant strain of the malaria vector, Anopheles gambiae. Gene 318:91-102 (2003).

36 Zhu YC and Snodgrass GL, Cytochrome P450 CYP6X1 cDNAs and mRNA expression levels in three strains of the tarnished plant bug Lygus lineolaris (Heteroptera: Miridae) having different susceptibilities to pyrethroid insecticide. Insect Mol Biol 12:39-49 (2003).

37 Yang Y, Chen S, Wu S, Yue L and Wu Y, Constitutive overexpression of multiple cytochrome P450 genes associated with pyrethroid resistance in Helicoverpa armigera. J Econ Entomol 99:1784-1789 (2006).

38 Djouaka RF, Bakare AA, Coulibaly ON, Akogbeto MC, Ranson H, Hemingway $J$ et al., Expression of the cytochrome P450s, CYP6P3 and CYP6M2 are significantly elevated in multiple pyrethroid resistant populations of Anopheles gambiae s.s. from southern Benin and Nigeria. BMC Genomics 9:538 (2008).

39 Bariami V, Jones CM, Poupardin R, Vontas J and Ranson H, Gene amplification, $A B C$ transporters and cytochrome P450s: unraveling the molecular basis of pyrethroid resistance in the dengue vector, Aedes aegypti. PLoS Negl Trop Dis 6:e1692 (2012).

40 Stevenson BJ, Pignatelli P, Nikou D and Paine MJI, Pinpointing P450s associated with pyrethroid metabolism in the dengue vector, Aedes aegypti: developing new tools to combat insecticide resistance. PLoS Negl Trop Dis 6:e1595 (2012).

41 Fragoso DB, Guedes RNC and Rezende ST, Glutathione S-transferase detoxification as a potential pyrethroid resistance mechanism in the maize weevil, Sitophilus zeamais. Entomol Exp Appl 109:21-29 (2003).

42 Fragoso DB, Guedes RNC, Goreti A and Oliveira M, Partial characterization of glutathione S-transferases in pyrethroid-resistant and -susceptible populations of the maize weevil, Sitophilus zeamais. J Stored Prod Res 43:167170 (2007).

43 Lumjuan N, Rajatileka S, Changsom D, Wicheer J, Leelapat P, Prapanthadara $L$ et al., The role of the Aedes aegypti Epsilon glutathione transferases in conferring resistance to DDT and pyrethroid insecticides. Insect Biochem $\mathrm{Mol}$ Biol 41:203-209 (2011).

44 Chigure GM, Sharma AK, Kumar S, Fular A, Sagar SV, Nagar G et al., Role of metabolic enzymes in conferring resistance to synthetic pyrethroids, organophosphates, and phenylpyrazole compounds in Rhipicephalus microplus. Int J Acarol 44:28-34 (2018).

45 Souza D, Vieira BC, Fritz BK, Hoffmann WC, Peterson JA, Kruger GR et al., Western corn rootworm pyrethroid resistance confirmed by aerial application simulations of commercial insecticides. Sci Rep 9: 6713 (2019). 
46 Goff SA, Vaughn M, McKay S, Lyons E, Stapleton AE, Gessler D et al., The iPlant collaborative: cyberinfrastructure for plant biology. Front Plant Sci 2:1-16 (2011).

47 Merchant N, Lyons E, Goff S, Vaughn M, Ware D, Micklos D et al., The iPlant collaborative: cyberinfrastructure for enabling data to discovery for the life sciences. PLoS Biol 14:e1002342 (2016).

48 Bolger AM, LohseMand Usadel B, Trimmomatic: a flexible trimmer for Illumina sequence data. Bioinformatics 30:2114-2120 (2014).

49 Andrews S, FastQC: a quality control tool for high throughput sequence data. 2016. http://www.bioinformatics.babraham.ac.uk/ projects/fastqc.

50 Kim D, Langmead B and Salzberg SL, HISAT: a fast spliced aligner with low memory requirements. Nat Methods 12:357-360 (2015).

51 Pertea M, Pertea GM, Antonescu CM, Chang T-C, Mendell JT and Salzberg SL, StringTie enables improved reconstruction of a transcriptome from RNA-seq reads. Nat Biotechnol 33:290-295 (2015).

52 Pertea M, Kim D, Pertea GM, Leek JT and Salzberg SL, Transcript-level expression analysis of RNA-seq experiments with HISAT, StringTie and Ballgown. Nat Protoc 11:1650-1667 (2016).

53 Bray NL, Pimentel H, Melsted P and Pachter L, Near-optimal probabilistic RNAseq quantification. Nat Biotechnol 34:525-527 (2016).

54 Pimentel H, Bray NL, Puente S, Melsted P and Pachter L, Differential analysis of RNA-seq incorporating quantification uncertainty. Nat Methods 14:687-690 (2017).

55 Rice P, Longden I and Bleasby A, EMBOSS: the European molecular biology open software suite. Trends Genet 16:276-277 (2000).

56 Altschul SF, Madden TL, Schäffer AA, Zhang J, Zhang Z, Miller W et al., Gapped BLAST and PSI-BLAST: a new generation of protein database search programs. Nucleic Acids Res 25:3389-3402 (1997).

57 Jones P, Binns D, Chang H-Y, Fraser M, Li W, McAnulla C et al., Inter- ProScan 5: genome-scale protein function classification. Bioinformatics 30:1236-1240 (2014).

58 Poelchau M, Childers C, Moore G, Tsavatapalli V, Evans J, Lee C-Y et al., The i5k workspace@NAL—enabling genomic data access, visualization and curation of arthropod genomes. Nucleic Acids Res 43: D714-D719 (2015).

59 Li H, Handsaker B, Wysoker A, Fennell T, Ruan J, Homer N et al., The sequence alignment/map format and SAMtools. Bioinformatics 25: 2078-2079 (2009).

60 Milne I, Stephen G, Bayer M, Cock PJA, Pritchard L, Cardle L et al., Using tablet for visual exploration of second-generation sequencing data. Brief Bioinform 14:193-202 (2013).

61 Notredame C, Higgins DG and Heringa J, T-coffee: a novel method for fast and accurate multiple sequence alignment. J Mol Biol 302: 205-217 (2000).

62 Letunic I and Bork P, 20 years of the SMART protein domain annotation resource. Nucleic Acids Res 46:D493-D496 (2017). 
63 Finn RD, Clements J and Eddy SR, HMMER web server: interactive sequence similarity searching. Nucleic Acids Res 39:W29-W37 (2011).

64 Potter SC, Luciani A, Eddy SR, Park Y, Lopez R and Finn RD, HMMER web server: 2018 update. Nucleic Acids Res 46:W200-W204 (2018).

65 Krogh A, Larsson B, von Heijne $G$ and Sonnhammer EL, Predicting transmembrane protein topology with a hidden Markov model: application to complete genomes. J Mol Biol 305:567-580 (2001).

66 Koressaar T and Remm M, Enhancements and modifications of primer design program Primer3. Bioinformatics 23:1289-1291 (2007).

67 Untergasser A, Cutcutache I, Koressaar T, Ye J, Faircloth BC, Remm M et al., Primer3-new capabilities and interfaces. Nucleic Acids Res 40: e115 (2012).

68 Kearse M, Moir R, Wilson A, Stones-Havas S, Cheung M, Sturrock S et al., Geneious basic: an integrated and extendable desktop software platform for the organization and analysis of sequence data. Bioinformatics 28:1647-1649 (2012).

69 Adelman ZN, Kilcullen KA, Koganemaru R, Anderson MAE, Anderson TD and Miller DM, Deep sequencing of pyrethroidresistant bed bugs reveals multiple mechanisms of resistance within a single population. PLoS One 6:e26228 (2011).

70 Li X, Schuler MA and Berenbaum MR, Molecular mechanisms of metabolic resistance to synthetic and natural xenobiotics. Annu Rev Entomol 52:231-253 (2007).

71 Puinean AM, Foster SP, Oliphant L, Denholm I, Field LM, Millar NS et al., Amplification of a cytochrome P450 gene is associated with resistance to neonicotinoid insecticides in the aphid Myzus persicae. PLoS Genet 6:e1000999 (2010).

72 Bass C, Zimmer CT, Riveron JM, Wilding CS, Wondji CS, Kaussmann M et al., Gene amplification and microsatellite polymorphism underlie a recent insect host shift. Proc Natl Acad Sci USA 110:19460-19465 (2013).

73 Feyereisen R, Insect P450 enzymes. Annu Rev Entomol 44:507-533 (1999).

74 Georghiou GP, The evolution of resistance to pesticides. Annu Rev Ecol Syst 3:133-168 (1972).

75 Roush RT and McKenzie JA, Ecological genetics of insecticide and acaricide resistance. Annu Rev Entomol 32:361-380 (1987).

76 Meinke LJ, Sappington TW, Onstad DW, Guillemaud T, Miller NJ, Komáromi J et al., Western corn rootworm (Diabrotica virgifera virgifera LeConte) population dynamics. Agric For Entomol 11:29-46 (2009).

77 ffrench-Constant $\mathrm{RH}$, The molecular genetics of insecticide resistance. Genetics 194:807-815 (2013).

78 Devonshire AL and Moores GD, A carboxylesterase with broad substrate specificity causes organophosphorus, carbamate and pyrethroid resistance in peach-potato aphids (Myzus persicae). Pest Biochem Physiol 18:235-246 (1982). 
79 Zhou X, Scharf ME, Sarath G, Meinke LJ, Chandler LD and Siegfried BD, Partial purification and characterization of a methyl-parathion resistance-associated general esterase in Diabrotica virgifera virgifera (Coleoptera: Chrysomelidae). Pest Biochem Physiol 78:114-125 (2004).

80 Carvalho RA, Omoto C, Field LM, Williamson MS and Bass C, Investigating the molecular mechanisms of organophosphate and pyrethroid resistance in the fall armyworm Spodoptera frugiperda. PLoS One 8:e62268 (2013).

81 Vontas JG, Small GJ and Hemingway J, Comparison of esterase gene amplification, gene expression and esterase activity in insecticide susceptible and resistant strains of the brown planthopper, Nilaparvata lugens (Stål). Insect Mol Biol 9:655-660 (2000).

82 Cui F, Lin Z, Wang H, Liu S, Chang H, Reeck G et al., Two single mutations commonly cause qualitative change of nonspecific carboxylesterases in insects. Insect Biochem Mol Biol 41:1-8 (2011).

83 Hemingway J, The molecular basis of two contrasting metabolic mechanisms of insecticide resistance. Insect Biochem Mol Biol 30: 1009-1015 (2000).

84 Casida JE, Gammon DW, Glickman AH and Lawrence LJ, Mechanisms of selective action of pyrethroid insecticides. Annu Rev Pharmacol Toxicol 23:413-438 (1983).

85 Lai K, Stolowich NJ and Wild JR, Characterization of P-S bond hydrolysis in organophosphorothioate pesticides by organophosphorus hydrolase. Arch Biochem Biophys 318:59-64 (1995).

86 Tang J, Rose Randy L and Chambers JE, Metabolism of organophosphorus and carbamate pesticides, in Toxicology of Organophosphate \& Carbamate Compounds, ed. by Gupta RC. Academic Press, Burlington, pp. 127-143 (2006).

87 Tabashnik BE, Mota-Sanchez D, Whalon ME, Hollingworth RM and Carrière $Y$, Defining terms for proactive management of resistance to Bt crops and pesticides. J Econ Entomol 107:496-507 (2014).

88 Landstrom AP, Beavers DL and Wehrens XHT, The junctophilin family of proteins: from bench to bedside. Trends Mol Med 20:353-362 (2014).

89 Calpena E, López Del Amo V, Chakraborty M, Llamusí B, Artero R, Espinós C et al., The Drosophila junctophilin gene is functionally equivalent to its four mammalian counterparts and is a modifier of a huntingtin poly- $Q$ expansion and the notch pathway. Dis Model Mech 11:1-13 (2018).

90 Hope KA, LeDoux MS and Reiter LT, Glial overexpression of Dube3a causes seizures and synaptic impairments in drosophila concomitant with down regulation of the $\mathrm{Na}+\mathrm{K}+$ pump ATP৬. Neurobiol Dis 108:238-248 (2017).

91 Bland ND, Pinney JW, Thomas JE, Turner AJ and Isaac RE, Bioinformatic analysis of the neprilysin (M13) family of peptidases reveals complex evolutionary and functional relationships. BMC Evol Biol 8: 16 (2008).

92 Meyer H, Panz M, Zmojdzian M, Jagla K and Paululat A, Neprilysin 4, a novel endopeptidase from Drosophila melanogaster, displays distinct substrate specificities and exceptional solubility states. J Exp Biol 212:3673-3683 (2009). 
93 Klein C, Patte-Mensah C, Taleb O, Bourguignon J-J, Schmitt M, Bihel F et al., The neuroprotector kynurenic acid increases neuronal cell survival through neprilysin induction. Neuropharmacology 70:254-260 (2013).

94 Pittendrigh B, Reenan R, Ffrench-Constant RH and Ganetzky B, Point mutations in the drosophila sodium channel gene Para associated with resistance to DDT and pyrethroid insecticides. Mol Gen Genet 256:602-610 (1997).

95 Martinez-Torres D, Foster SP, Field LM, Devonshire AL and Williamson MS, A sodium channel point mutation is associated with resistance to DDT and pyrethroid insecticides in the peach-potato aphid, Myzus persicae (Sulzer) (Hemiptera: Aphididae). Insect Mol Biol 8:339-346 (1999).

96 Brooke $\mathrm{BD}, \mathrm{Kdr}$ : can a single mutation produce an entire insecticide resistance phenotype? Trans R Soc Trop Med Hyg 102:524-525 (2008).

97 Daborn P, Boundy S and Yen J, Pittendrigh B, and ffrench-Constant R, DDT resistance in drosophila correlates with Cyp6g1 overexpression and confers cross-resistance to the neonicotinoid imidacloprid. Mol Genet Genomics 266:556-563 (2001).

98 Daborn PJ, Yen JL, Bogwitz MR, Goff GL, Feil E, Jeffers S et al., A single P450 allele associated with insecticide resistance in Drosophila. Science 297:22532256 (2002).

99 Brandt A, Scharf M, Pedra JHF, Holmes G, Dean A, Kreitman M et al., Differential expression and induction of two drosophila cytochrome P450 genes near the Rst(2)DDT locus. Insect Mol Biol 11:337-341 (2002).

100 Le Goff G, Boundy S, Daborn PJ, Yen JL, Sofer L, Lind R et al., Microarray analysis of cytochrome P450 mediated insecticide resistance in drosophila. Insect Biochem Mol Biol 33:701-708 (2003). 